\title{
TECCIENCIA
}

\section{Touch interface analysis for virtual reality}

\section{Análisis de interfaces táctiles para realidad virtual}

\author{
Jhon Edwin Vera ${ }^{1}$, Jhon Fredy Bayona ${ }^{2}$, Andres Torres ${ }^{3}$ \\ ${ }^{1}$ Escuela Colombiana de carreras industriales, Bogotá, Colombia, jhonedu032@ hotmail.com \\ ${ }^{2}$ Escuela Colombiana de carreras industriales, Bogotá, Colombia, ingbayona@ hotmail.com \\ ${ }^{3}$ Escuela Colombiana de carreras Industriales, Bogotá, Colombia, jaavito@gmail.com
}

\begin{abstract}
In control is common talk of point operation for stability of systems. These paper your mind the model haptic and interface analyzing the signals input and output. Is important highlight that in market there many applications on the same principle and important that have in changing industry. Works according to two ports for achieve system stability by means of some variables and analyzes the communication through different interfaces.
\end{abstract}

Keywords: Touch, bioengineering, Stability, virtual environment

\section{Resumen}

El propósito de este trabajo es realizar un análisis detallado para la implementación de sistemas virtuales en aplicaciones médicas, se estudia el principio de estabilidad y control para diseñar entornos virtuales táctiles con res grados de libertad en su movilidad, se muestran algunos de los parámetros fundamentales para cualquier aplicación virtual como: el modelo, las impedancias, la estabilidad y el control, con el fin de orientar estas aplicaciones en prototipos de la Escuela Colombiana de carreras industriales a nivel de Bioingeniería.

Palabras Clave: Táctiles, Bioingeniería, estabilidad, entornos virtuales.

\section{Introduction}

This paper analyzes the stability and controllability parameters oriented to the touch systems (haptics), in order to implement them in the future for different applications. The modeling touch system is developed considering quantifications of design and operation under three degrees of freedom.

The fundamental principle of touch applications [1] [2] shows the development in virtual environments and its importance in future technologies. The first point is raised in detail ports studying a model known as Excalibur which seeks to interact with an external model and visualize through a computer with different response variables. Some applications known as mouse movement, keyboard management among others are the beginning of these types of applications [3].

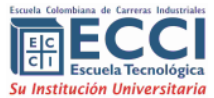

The problem in EXCALIBUR model lies in the fact that stability is greatly affected by the application software and the nature of human beings that are in contact with the device. The application software or the "virtual environment" determines what forces are presented through the touch screen of the human operator.

It is clear that control development is given by the virtual environment but the absolute complexity is evaluated according to the physical variables that can affect it as speed and strength in exchange of information relating interfaces. In a sense, touch interaction is very different from other systems of human-computer interface. The principle of this system is studied to guide future work systems at medical and bioengineering applications.

How to cite: Vera, J.; Bayona, J.; Torres, A.,Touch interface analysis for virtual reality, TECCIENCIA, Vol. 7 No. 14., 61-64, 2013, DOI: http:/dx.doi.org/10.18180/tecciencia.2013.14.8 


\section{Excalibur model}

The Excalibur model is based on a manipulator of three degrees of freedom it is designed to act as a touch interface and the idea is that it can be manipulated by a handle, the device is capable of making very large peak forces and working largely analyzing the input signals and output signals. [3]

The dynamics of the system can be represented on a second order differential equation:

$$
M \ddot{q}(t)+D \dot{q}(t)+K q(t)=G u(t)
$$

Where $\mathrm{M}, \mathrm{D}, \mathrm{K}$ are the mass, damping and stiffness matrices and $\mathrm{G}$ is the distribution control matrix which represents internal state vector and $u$ is the input vector [4]. The equations governing the system can be represented by the place and in that way define the transfer functions. The matrix is raised in such way that the first row belongs to the output corresponding to the variables and the second to the input.

$$
\begin{gathered}
{\left[\begin{array}{c}
v_{h}(s) \\
-v_{a}(s)
\end{array}\right]=\left[\begin{array}{c:c}
Y_{h h}(s) & Y_{h a}(s) \\
Y_{a h}(s) & Y_{a a}(s)
\end{array}\right]\left[\begin{array}{l}
f_{h}(s) \\
f_{a}(s)
\end{array}\right]} \\
f_{m}(s)=\left[\begin{array}{ll}
F_{m h}(s) & \left.F_{m a}(s)\right]
\end{array}\right]\left[\begin{array}{l}
f_{h}(s) \\
f_{a}(s)
\end{array}\right]
\end{gathered}
$$

\section{Interface design touch}

The touch interface is more than just the mechanical device covering everything that comes between the human operator and the virtual environment. To better understand the stability properties of the system, the touch interface is separated into a cascade combination of two subnets. [5] The first one, the touch screen and the second virtual coupling which is shown in Figure 2 given an idea of the analysis of the variables and the interaction that they may have.

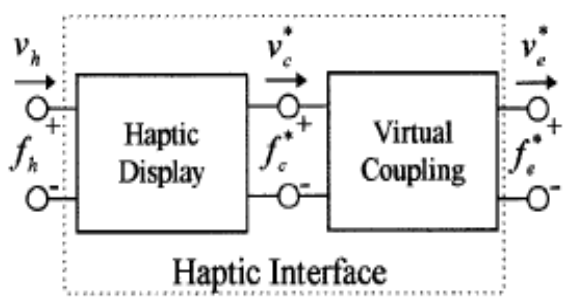

Figure 1. Two port interface haptic

\subsection{Implementations of the touch screen}

The touch screen (Haptic Display) includes the physical structure of the manipulator as well as actuators, sensors, analog filters, amplifiers, digitalanalog converters, digital, digital filtering, and control software.

A physical port is found, the human operator handling exchanges energy with the screen. At the other end there is a port information which is characterized by discrete variables, speed and strength, $\mathrm{V} * \mathrm{c}$ and $\mathrm{f} * \mathrm{c}$ [6]. Unlike the physical port specific causation must be associated with port information.

The touch screen which can measure the movement and show the strength or force can be measured and show movement. The first case is an impedance screen where $\mathrm{v} * \mathrm{c}$ is an output $\mathrm{f} * \mathrm{c}$ is an input. The latter case is an admittance screen where $\mathrm{v} * \mathrm{c} *$ is an input $\mathrm{f} \mathrm{c}$ is a given output keeping in mind the impedance and the admittance. Figure 3 shows one of the most common systems for this kind of implementation. [7]

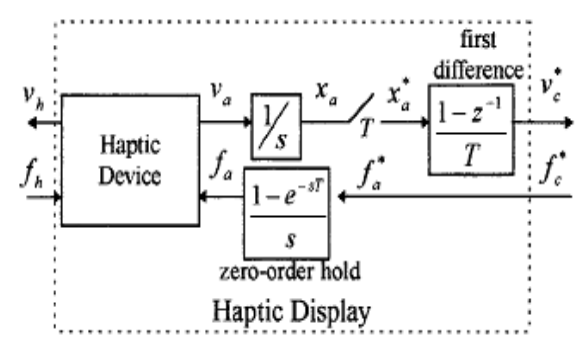

Figure 2. .Implementation of screen impedance

\subsection{Deploying virtual coupling}

The virtual network link is the artificial link between the touch screen and the virtual environment. Coupling the virtual network is an additional element of control designed in a way that the touch interface is quite stable. In principle, this can be a general function of two ports and in practice by limiting the choice of these network topologies can be found the design criteria for the coupling function.

For the impedance screen are consider the two ports with a single impedance (ZCI (z)) and for admittance display virtual coupling would be limited to a simple series impedance (ZCA (z)). In Figure 5 shows the 


\section{TECCIENCIA}

four possible implementations of the virtual coupling characterizing the system for control and stability analysis.
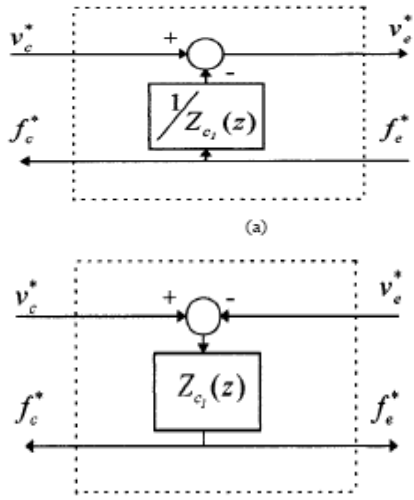

(b)

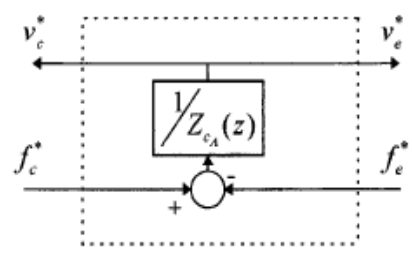

(c)

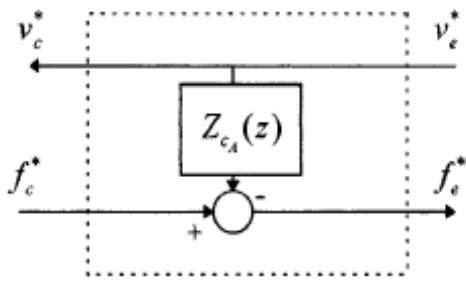

(d)

Figure 3. Implementation of virtual coupling.

\section{Stability and control framework}

The stability and control framework is analyzed taking into account different variables depending on the port. Three degrees of freedom are defined and the system is characterized.

Equation (3) shows the impedance analysis cupping to ensure system stability as $\operatorname{Re}(1 / \mathrm{Zc} 1)$ and admittance $\mathrm{Y} *$ as a discrete variable [3].

$$
e\left(1 / Z_{C_{1}}\left(e^{s T}\right)\right) \geq \frac{\left|Y_{h c}^{*}(s) Y_{c h}^{*}(s)\right|+\operatorname{Re}\left(Y_{h c}^{*}(s) Y_{c h}^{*}(s)\right)}{2 \operatorname{Re}\left(Y_{h h}(s)\right)}
$$

These conditions arise from the combination of impedances coupled to the coupling network and the virtual generated matrix.

$$
\left[\begin{array}{c}
v_{h}(s) \\
-v_{e}^{*}(s)
\end{array}\right]=\left[\begin{array}{c:c}
Y_{h h}(s) & Y_{h c}^{*}(s) \\
\hdashline Y_{c h}^{*}(s) & Y_{c h}^{*}(s)+\frac{1}{z_{c_{1}}\left(e^{S T}\right)}
\end{array}\right]\left[\begin{array}{l}
f_{h}(s) \\
f_{e}^{*}(s)
\end{array}\right]
$$

Figure 5 shows the interaction model which serves as a reference to define the interface between the human operator and the computer. The method defines two ports and is based on the theory of linear circuits used to characterize the effect of different load conditions at two terminals of electrical networks [6]. In other words what it is trying to do is generate the system equations according to physical variables such as speed and strength. Then the human operator affects the speed, strength and physical point of contact with the touch screen, the virtual environment modulates the speed and strength at the point of exchange of information.

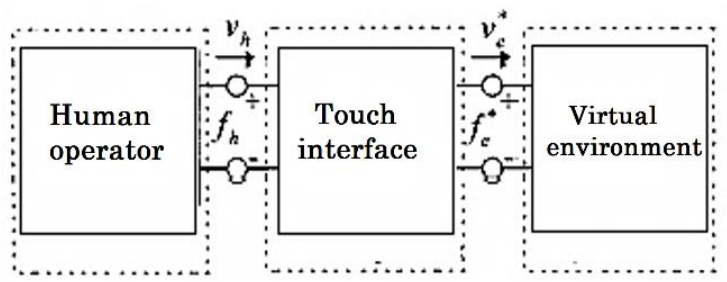

Figure 4. Interaction Model

\section{Conclusions}

To obtain numerical results for both the screen impedance and the admittance screen, virtual couplings were used in order to make the touch interface absolutely stable. The experimental results have been tested in the VBB systems (virtual building block) which are used to simulate the handling and strength through virtual blocks.

Impedance couplings are an important factor for controlling the systems, but should take into account the losses due to parasitic inductances and capacitances. It is important to note that the developed system does not understand the nonlinearities and may have future improvements for accuracy. The management and measurement of variables for virtual environments show the ability of these systems to be 


\section{TECCIENCIA}

projected into the field of medicine as a future alternative.

\section{References}

[1] C. Edmond, D. Heskamp, D. Sluis, D. Stredney, D. Sessanna, G. Wiet, R. Yagel, S. Weghorst, P. Oppenheimer, J. Miller, M. Levin y L. Rosenberg, «ENT Endoscopic surgical training simulator,» de Studies in health technology and informatics , Tacoma, 1997.

[2] R. Baumann y R. Clavel, «Haptic interface for virtual reality based minimally invasive surgery simulation,» de Proc IEEE international conference Robot automatization , 1998.

[3] R. J. Adams y B. Hannaford, «Stable Haptic Interaction with virtual Environments,» IEEE transactions on robotics and automation, vol. 15, $\mathrm{n}^{\circ} 3$, pp. 465-474, 1999.
[4] R. J. Adams, M. R. Moreyra y B. Hannaford, «Excalibur, A three-axis force display,» de Proc ASSME symposium Haptic interfaces, Nashville, 1999.

[5] R. J. Adams y B. Hannaford, «Control Law design for haptic interfaces to virtual reality,» Control Systems Technology, vol. volumen 10, nº 1, pp. 3-13, 2002.

[6] R. J. Adams, D. Klowden y B. Hannaford, «Stable haptic interaction using the excalibur force display,» de Robotichs and automation, 2000. Proceedings. ICRA 'OO IEEE International conference on, San Francisco, 2000.

[7] J. E. Colgate y J. M. Brown, «Factors affecting the Z-width of a haptic display,» de Robotics and Automation, 1994. Proceedings., 1994 IEEE International Conference on, San Diego, 1994. 